\title{
Towards a Compositional Semantics for Locative Modifiers
}

\author{
Claudia Maienborn \\ Humboldt University of Berlin, Germany
}

\begin{abstract}
Summary
Within linguistic theory, very little effort has been devoted so far to a comprehensive theory of the syntax and semantics of modifiers. It is predominantly assumed that modifiers make a constant semantic contribution to the meaning of the constituent that is modified, irrespective of any conceivable syntactic differentiations. This account cannot cope with a multitude of empirical data and should therefore be replaced by a theory of modification that pays more attention to the exact nature of a given syntactic configuration and its impact on semantic composition. The approach advocated here is illustrated with locative modifiers of verb phrases. It will be shown that these expressions have a large range of meaning variability. Using German data, it is argued that differences in meaning can be correlated with differences in syntactic structure. On this basis, a compositional semantics for locative modifiers is proposed.
\end{abstract}

\section{The Data}

Let us first have a look at the relevant data in the examples (1) to (3). The locative modifier under consideration is always marked by underlining. 1

(1) a. Die Kinder spielen vor dem Haus Fußball.

'The children play in-front-of the house soccer.'

b. Die irische Mannschaft hat das italienische Team in New York mit 1:0

'The Irish team has the Italian team in New York with 1:0 defeated.'

c. Auf dem Hof hat es gebrannt.

'On the yard has EXPL burned.' (There was a fire in the yard.)

(2) a. Die Touristen verließen das Urwalddorf in einem Motorboot.

'The tourists left the virgin-forest-village in a motor-boat.'

b. Maria zog Paul am Kragen in den Flur.

'Mary dragged Paul at.the collar into the corridor.'

(Mary dragged Paul into the corridor by the collar.)

c. Paul steht auf dem Kopf.

'Paul stands on the head.' (Paul is standing on his head.)

(3) a. In den USA ist Fußball eine eher unbeliebte Sportart. 'In the USA is soccer a rather unpopular sport.'

b. Paul ist zuhause ziemlich faul.

'Paul is at-home quite lazy.'

c. In Frankfurt ist die Einwohnerzahl gesunken.

'In Frankfurt has the population decreased.' 
Locative modifiers of verb phrases are generally associated with expressions of the type exemplified in (1). In (1.a), for instance, the locative modifier expresses that a situation consisting of children playing soccer takes place in a certain spatial region, namely in front of a contextually determined house. Roughly, what a locative modifier does in expressions of type (1) is locate the situation denoted by the VP in space. This type of semantic contribution of a locative VPmodifier is the only variant that is commonly noticed in the relevant literature; $\mathrm{cf}$. e.g. Bierwisch (1988), Wunderlich (1991), Wunderlich \& Herweg (1991). But already a brief look at the examples under (2) and (3) reveals that this is by no means the only existing option.

In the sentences under (2), the locative modifier (in its preferred reading) does not provide a location for the whole situation. For instance, in (2.b) it is not the situation consisting of Mary dragging Paul into the corridor that is located at the collar. What the locative modifier does instead is specify the corresponding situation further and elaborate its internal structure by expressing a spatial relationship holding within that situation. So, when taking into account sentences of type (2), we are faced with a large and rather heterogeneous looking class of cases in which the specific semantic contribution of the locative modifier depends crucially on the meaning of the verb and further contextual settings. In fact, sometimes we might even wonder whether the locative preposition preserves its regular semantics in such cases.

Finally, a third type of locative VP-modifier can be singled out when looking at the examples under (3). Here, the semantic contribution of the locative modifier is only indirectly related to the VP meaning: It restricts spatially the range in which the proposition expressed by the rest of the sentence holds true. Sentence (3.a), e.g., makes the claim that, with respect to the USA, soccer is a rather unpopular sport. That is, the locative modifier provides a certain kind of spatial frame for the proposition. Notice that, contrary to the locative modifiers in sentences (1) and (2), modifiers of the type exemplified in (3) do not fit into the inference pattern commonly assumed to hold for intersective modifiers; cf. e.g. Higginbotham (1985). For instance, from the truth of the sentences (1.a) and (2.a.) follows the truth of (1'.a ) and (2'.a), respectively. But, given e.g. (3.a), we are not allowed to infer ( $\left.3^{\prime} . a\right)$; cf. Maienborn (1993) for further peculiarities concerning the inferential behavior of the locative modifiers exemplified in (3).

(1') a. Die Kinder spielen Fußball.

(The children are playing soccer.)

(2') a. Die Touristen verließen das Urwalddorf.

(The tourists left the virgin-forest-village.)

(3') a. Fußball ist eine eher unbeliebte Sportart.

(Soccer is a rather unpopular sport.)

The evidence presented so far leads to the assumption of three major classes which have to be distinguished properly when dealing with the semantics of locative VP-modifiers. For the sake of simplicity, I will refer to them as type (1), type (2), and type (3) modifiers, respectively. These kinds of meaning differences show up systematically, in German. Therefore, they cannot be traced back to idiosyncrasies of the prepositions or verbs involved. Thus, we have to account for the fact that meaning composition with locative modifiers and verbal phrases is apparently subject to different modes of semantic combination.

Given the range of possible interpretations for locative VP-modifiers, we should expect that ambiguities might arise as well. This is actually the case, as can be shown by the examples (4) and (5). 
(4) Angela hat sich mit Dirk im Museum verabredet. 'Angela has REFL with Dirk in.the museum arranged-to-meet.' (Angela has made an appointment with Dirk in the museum.)

(5) Die Gebäcke sind in unserer Bäckerei frisch hergestellt. 'The cookies are in our bakery freshly produced.'

Sentence (4) has two readings. In the first reading, the modifier expresses that a situation of making an appointment takes place in the museum. (It might be an appointment for going to the cinema, for instance.) In the second reading, the modifier specifies the location of the arranged meeting, thereby supplying further information about the appointed event. That is, the locative modifier in (4) can be interpreted either as type (1) or as type (2) modifier. Sentence (5), on the other hand, is ambiguous in the sense that the locative modifier might have either a type (1) reading, which roughly means that a situation of producing fresh cookies is located in a certain bakery, or it might obtain a type (3) reading, saying that for a certain bakery it holds true that their cookies are freshly produced (where ever the place of production itself might be).

Interestingly, the distinct readings of (4) and (5) go along with different accent patterns under neutral stress conditions. ${ }^{2}$ In the case of sentence (4), the type (1) reading is associated with primary sentence accent on the verb (cf. (4.a)), whereas the type (2) reading requires primary sentence accent on the modifier (cf. (4.b)). ${ }^{3}$

(4) a. Angela hat sich mit Dirk im Museum VERABREDET.

b. Angela hat sich mit Dirk im MUSEUM verabredet.

Likewise, the type (1) reading of (5) is associated with primary sentence accent on the verb (cf. (5.a)). The type (3) reading, on the other hand, requires primary accent on the adverb and - due to the particular word order in (5) - a secondary, contrastive stress on the pronoun. (Issues of stress and word order will be discussed in some more detail in Section 3.)

(5) a. Die Gebäcke sind in unserer Bäckerei frisch HERGESTELLT.

b. Die Gebäcke sind in UNSERER Bäckerei FRISCH hergestellt.

To conclude this brief overview of the relevant data let us have a look at the sentences in (6) and (7). Here, we are faced with the somewhat puzzling problem that besides its genuine meaning contribution of expressing a spatial relationship, a locative modifier of type (2) or (3) might make an additional non-spatial meaning contribution. In particular, type (2) modifiers often convey instrumental or manner information (cf. (6)), whereas type (3) modifiers may obtain a temporal or conditional reading (cf. (7)).

(6) a. Die Bankräuber sind auf Fahrrädern geflüchtet.

'The bank-robbers have on bicycles fled.'

b. Der Koch hat die Hähnchen in einer Marihuana-Tunke zubereitet. 'The cook has the chickens in a Marihuana sauce prepared.'

(7) a. In Bolivien hatte Maria rotes Haar. 'In Bolivia - had Mary red hair.'

b. Im Bett sind die Kinder sehr brav.

'In.the bed are the children very well-behaved.' 
In (6.a) the modifier takes on additionally an instrumental reading. It supplies information about the means of transport that was used by the bank robbers. Therefore, it could be replaced by a genuine instrumental phrase like with the $c a b$. The locative modifier in (6.b) specifies a particular mode of preparing the food. That is, it conveys some sort of manner information. The type (3) modifier in (7.a) suggests a temporal interpretation. Thus, (7.a) might be paraphrased as „When Mary was in Bolivia, she had red hair.« And, finally, (7.b) might get a conditional interpretation as is indicated by the paraphrase »If the children are in bed, they are very well-behaved. « A comprehensive theory of modification should account for these non-spatial meaning relations that are superimposed on the regular spatial expression in the case of type (2) and type (3) modifiers. And it should make clear, furthermore, why type (1) modifiers never exhibit such a behavior.

\section{General Approach}

What are the requirements that have to be met by such a theory? Two conditions should be mentioned concerning grammar and the lexicon, which I assume to be crucial for any semantic theory that aims at generalizations. The first condition is that grammar should license some sort of compositionality. The second condition imposes parsimony on the lexicon. That is, we have to dispense e.g. with the assumption of polysemy unless it is really well-motivated. In the case under discussion, it would not be promising to cope with the observed meaning differences by simply stipulating multiple lexical entries for verbs or prepositions. Obviously, we are looking for more principled approaches to lexical semantic structures. Indeed, we should adhere to the assumption of unambiguous lexical entries as far as possible. But then it becomes clear that the data presented above are a real challenge to semantic theory. In what follows, we shall see how far we can get with a semantics for locative modifiers that takes lexical economy as well as compositionality seriously.

The theoretical framework that will serve as the foundation of the approach is given by the so-called "Two-level Semantics" developed by Manfred Bierwisch and Ewald Lang; cf. e.g. Bierwisch (1982), Bierwisch \& Lang (1989). Within this framework, two levels of meaning representation are distinguished on systematic grounds: a so-called "Semantic Form" (SF) which captures only those aspects of meaning that are relevant for syntax, and a conceptual structure (CS) which elaborates SF in terms of the extra-linguistic conceptual knowledge which is accessible in a certain context. That is, SF figures as a grammatically determined and context-independent meaning skeleton that provides the interface between grammar and the conceptual system. For the issue discussed here, it is relevant to add that SF is subject to the principle of compositionality, whereas non-compositional aspects of meaning are restricted to the level of CS. So, when dealing with the semantics of locative VP-modifiers we have to single out which aspects of the complex meaning belong to SF and which should be handled at CS. The following considerations will focus on the grammatically transparent part of the meaning of locative VP-modifiers, i.e. SF.

The hypothesis that forms the starting point of the present analysis of locative VP-modifiers says that there is also a genuine syntactic differentiation at work, besides the semantic distinction of SF and CS. The different accent patterns which disambiguate the possible readings of a locative modifier (cf. Section 1) have already given us some hint that grammatical structure might reflect the relevant meaning distinctions to some extent. So it is important to investigate whether there are clear syntactic distinctions that go along with the different readings. In the 
following Section, I will present some evidence that each of the three types of locative VP-modifiers actually takes a different syntactic base position. This finding provides the foundation for the subsequent semantic analysis.

\section{Syntactic Structure}

It is a well-known fact, that German exhibits rather free surface order and the relevant tests for determining base positions are quite subtle. Thus, we are well advised to use different heuristics that have been established on independent grounds. These will give us a relatively precise diagnostic when taken together. For the issue discussed here, suitable tests are based on data concerning focus projection, quantifier scope, as well as topicalization. In the following, each of the tests will be introduced briefly and its results for the case under investigation will be spotlighted by some illustrations. Afterwards, an overview of the main insights that can be gained for the syntactic structure of locative VP-modifiers will be given; $\mathrm{cf}$. Maienborn (1993) for a more thorough discussion of the subject matter.

Focus projection has become "the" standard word order test for German since the work of Höhle (1982). Höhle points out that normal word order allows for the greatest range of possible focus settings. In particular, normal word order allows focus to project from the focus exponent up to the entire sentence. On the other hand, focus projection is blocked when surface structure deviates from base order.

Given this device, let us check, for instance, the relative order of a locative VP-modifier of type (1) with respect to the direct object of the verb.

(8) Paul hat [PP vor dem Capitol] [DP die MARSEILLAISE] gesungen.

'Paul has in-front-of the Capitol the Marseillaise sung.'

a. What did Paul sing (in front of the Capitol)?

b. What did Paul do (in front of the Capitol)?

c. What happened?

(9) Paul hat [DP die Marseillaise] [PP vor dem CAPITOL] gesungen.

a. Where did Paul sing the Marseillaise?

In (8), the locative modifier precedes the direct object and primary sentence accent is placed on the constituent that is adjacent to the verb. This configuration allows focus to project up to the sentence level. That is, the sentence in (8) might be a plausible answer to all the questions listed in (8.a-c), including the question »What happened? « which presupposes maximal focus. With the reversed order in (9), focus projection is blocked. The sentence in (9) is only compatible with the question (9.a), which indicates narrow focus on the prepositional phrase. Thus, the focus projection test indicates that locative modifiers of type (1) precede direct objects in base order.

Completely different results are obtained if a type (2) modifier is taken instead. Here, focus projection and therefore normal word order is ensured only in case the locative modifier is placed behind the direct object and adjacent to the verb (cf. (10)). The reverse order leads to a highly marked sentence structure that, if accepted at all, needs a strong contrastive accent on the direct object (cf. (11)). Therefore, we may conclude that type (2) modifiers have a base position configurationally below the direct object and close to the verb. 
(10) Die Spieler haben [DP den Torschützen] [PP auf den SCHULTERN] getragen. 'The players have the scorer on the shoulders carried.' (The players carried the scorer on their shoulders.)

a. Where/How did the players carry the scorer?

b. What did the players do w.r.t. the scorer?

c. What did the players do?

d. What happened?

(11) ?Die Spieler haben [PP auf den Schultern] [DP den TORSCHÜTZEN] getragen. a. Whom did the players carry on their shoulders?

Thus, the data presented so far already shows that type (1) and type (2) modifiers differ crucially with respect to the position they take relative to the direct object of the verb.

A second suitable diagnostic for base structure goes back to the work of Frey (1993) on binding and scope. Frey develops a surface oriented theory of quantifier scope which says that scope ambiguities only arise in case surface structure deviates from base order, always provided that other intervening factors, especially focus, are neutralized. A sentence like (12) is truly ambiguous. Either the universal quantifier or the existential quantifier might obtain wide scope.

(12) Paul hat [PP in fast jeder Konzerthalle] [DP mindestens ein Schubert-Lied]

'Paul has in nearly every concert hall at-least one Schubert song gesungen. sung.'

However, in order to get the wide scope reading of the existential quantifier, additional means have to be taken. This reading is only available with a specific focus setting, namely narrow focus on the existential quantifier (cf. (12')):

(12) $\exists \forall:$ Paul hat [PP in fast jeder Konzerthalle] [DP mindestens EIN Schubert-Lied] gesungen.

Frey proposes to preclude the influence that focus has on scope by placing the main accent on the finite verb or the complementizer. This focuses on the truth polarity of the sentence (so-called "Verum-Focus"), which suppresses any interaction of focus with scope and gives us the opportunity to single out what the purely syntactic conditions on scope assignment are. Frey's scope principle can be stated then as follows:

Scope principle (Frey 1993):

A quantifier phrase A has scope over a quantifier phrase $B$, if the head of the A-chain c-commands the foot of the B-chain.

This principle can be used as a tool for determining base structure because it says that, whenever we observe scope ambiguities, a quantified phrase must have been moved into a position where it c-commands a second quantifier which in turn still c-commands the trace of the first one.

Sentence (13.a) with a type (1) modifier preceding the direct object of the verb only allows the wide scope reading of the universal quantifier. Therefore, the surface order of the locative modifier and the direct object should correspond to their base order. Scope ambiguities do arise however, as soon as the order is reversed as in (13.b). This sentence allows for both scope readings. Consequently, the direct object must have been moved out of its base position below the prepositional phrase. 
(13) a. Paul HAT [PP in fast jeder Konzerthalle] [DP mindestens ein Schubert-Lied]

'Paul has in nearly every concert hall at-least one Schubert song sung.' $(\forall \exists)$

b. Paul HAT [DP mindestens ein Schubert-Lied] [PP in fast jeder Konzerthalle] gesungen. $(\exists \forall, \forall \exists)$

The use of a type (2) modifier leads to the inverse results. That is, scope ambiguities arise in (14.a) but not in (14.b).

(14) a. Paul HAT [PP in fast jeder Sänfte] [DP mindestens einen Pascha] getragen.

'Paul has in nearly every sedan-chair at-least one pasha carried.'

$(\forall \exists, \exists \forall)$

b. Paul HAT [DP mindestens einen Pascha] [PP in fast jeder Sänfte] getragen.

$(\exists \forall)$

Thus, both, the focus projection test and the quantifier scope test, converge in their results: Type (1) modifiers precede direct objects which in turn are followed by type (2) modifiers in base structure. The sample sentences in (15) and (16) may give us now some evidence concerning the relative ordering of type (1) and type (3) modifiers with respect to the subject of the sentence. From the data in (15) we may conclude that the subject precedes type (1) modifiers in base structure whereas type (3) modifiers take a base position that is higher than the subject position, as is shown by (16).

(15) a. [DP Mindestens ein Opernsänger] HAT [PP in fast jeder Konzerthalle]
'At-least one opera singer has
in nearly every concert hall
Schubert songs sung.' $(\exists \forall)$
b. [PP In fast jeder Konzerthalle] HAT [DP mindestens ein Opernsänger]
Schubert-Lieder gesungen. $(\forall \exists, \exists \forall)$

(16) a. [DP Fast jeder Opernsänger] IST [PP in mindestens einem Land] berühmt.

'Nearly every opera singer is in at-least one country famous.'

b. [PP In mindestens einem Land] IST [DP fast jeder Opernsänger] berühmt. $(\exists \forall)$

Finally, the VP-preposing data in (17) and (18) give additional evidence for different syntactic structures underlying VP-modification. As we have seen above, type (2) modifiers are base-generated in close proximity to the verb. In some sense, they are merged with the verb to build a complex predicate. This allows them to be topicalized together with the verb (cf. (17.a) and (18.a)). On the other hand, type (1) and type (3) modifiers do not form a complex unit with the verb. Therefore, joint topicalization is not acceptable. It leads to highly questionable structures for type (1) modifiers (cf. (17.b)) and it is ruled out completely in the case of type (3) modifiers (cf. (18.b)). ${ }^{4}$

(17) a. [Auf den Schultern getragen] haben nach dem Abpfiff die Spieler

den Torschützen.

'On thedar shoulders carried have after the final-whistle thenom players the AcC scorer.'

b.??[Auf dem Rasen getragen] haben nach dem Abpfiff die Spieler den Torschützen.

'On thedat lawn carried have after the final-whistle thenom players 
(18) a. [In Stiefeln geschlafen] haben die Cowboys im Wilden Westen. 'In boots slept have the cowboys in.the Wild West.'

b. *[Im Wilden Westen geschlafen] haben die Cowboys in Stiefeln. 'In.the Wild West slept have the cowboys in boots.'

Consequently, joint topicalization of the modifier and the verb also rules out the type (1) reading of an ambiguous sentence like (4). The structure in (19) is only compatible with the type (2) reading of the locative modifier. (That is, the sentence gets the interpretation that Angela has made an appointment with Dirk for the museum.)

(19) [Im Museum verabredet] hat Angela sich mit Dirk.

'In.the museum arranged-to-meet has Angela REFL with Dirk.'

The results concerning syntactic structure can be summarized as follows: First of all, there is evidence that not only arguments but also adjuncts have welldefined syntactic base positions, in German. Secondly, one and the same lexical category can exploit distinct adjunction sites. In the case of locative VP-modifiers, there are three base adjunction sites which correspond to different modes of semantic combination. 5 Leaving details aside, we can give the following syntactic characterization for the three types of locative VP-modifiers:

Type (1) modifiers have a base adjunction site between the subject and the verb's remaining arguments, at the periphery of VP (V'-adjuncts).

Type (2) modifiers have a base adjunction site in close proximity to the verb, i.e. configurationally below all arguments (V-ad juncts) ${ }^{6}$

Type (3) modifiers have a base adjunction site above all arguments of the verb and within the verbs extended projection by a functional category (IP-adjuncts). ${ }^{7}$

The syntactic distinction worked out so far provides the ground work for a compositional semantics of locative modifiers that is properly tuned to syntactic structure.

\section{Semantic Structure}

The semantic model developed here is based on a proposal by Higginbotham (1985) and further refinements made by Bierwisch (1988). Within this framework, (intersective) modification is handled by a single semantic operation that identifies the designated argument of the modifier with the referential argument of the modificandum by conjoining their semantic contributions. This definition captures the genuinely combinatorial part of the semantics of modification. In order to grasp the implications of the definition, as it stands, for locative VP-modifiers, we have to single out the modifier's designated argument and the verb's referential argument first.

The designated argument ${ }^{8}$ of a locative modifier refers to the entity that is to be located in space (henceforth abbreviated as: LE). ${ }^{9}$ The general schema for the Semantic Form of locative prepositions is shown in (20.a). The SF of e.g. the German preposition in is given in (20.b): 
(20) a. $P_{\text {LOK }}: \lambda y \underline{\lambda}[$ [ LOC (x, SPACE-FUNC (y))]

b. in: $\quad \lambda \mathrm{y} \lambda \underline{x}[\operatorname{LOC}(\mathrm{x}, \mathbb{I N}(\mathrm{y}))]$

The Semantic Form of a locative preposition is expressed by a relation LOC that holds between the designated argument $\mathrm{x}$ and a spatial region. This region is defined in turn by a characteristic space-function (SPACE-FUNC) that is applied to the preposition's internal argument $y$. In the case of in, the space-function IN maps the referential object (RO) referred to by the internal argument onto the inner region of RO. The relation LOC says that $\mathrm{x}$ is located in the corresponding region; cf. e.g. Bierwisch (1988), Wunderlich (1991).

Within a neo-Davidsonian approach, the referential argument of VP is provided by the situational referent s. (21.a) shows the general SF schema for situative verbs and (21.b) gives an illustration using the German verb geben (to give):
a. V:
$\ldots \lambda s[\mathrm{~s}$ INST $[\ldots]]$
b. geben:
$\lambda z \lambda y \lambda \underline{x} \lambda s$ [s INST [ CAUSE ( $x$, BECOME (POSS $(y, z))$ )]

The schema in (21.a) expresses that among the arguments of a situative verb, there is one referential argument, viz. the situational referent, which instantiates (INST) a proposition given by decomposing the verb's meaning into primitive predicates, as shown in (21.b); cf. e.g. Dowty (1979), Bierwisch (1988).

Having singled out the relevant arguments, we are now in the position to apply the principle of modification to the case of locative VP-modifiers: Following the definition given above, the designated argument of the prepositional phrase is identified with the situational referent of the verb. Consequently, the situational referent qualifies as the entity that is to be located. That is, VP-modification leads to the semantic structure given in (22), which states that a situation expressed by the VP is located in space. This is what follows from the general principle proposed by Higginbotham and Bierwisch.

\section{(22) Locative VP-modification: ... $\lambda$ s [ s INST [ ... ] \& LOC (s, SPACE-FUNC (RO))]}

Thus, the combinatorial schema presented so far can be said to account properly for the semantics of type (1) modifiers. But evidently, it fails with respect to type (2) and type (3) modifiers, since the semantic structure given in (22) figures as an uniquely admissible SF for locative VP-modification.

I will argue in the following that the original combinatorial schema needs only a slight modification in order to account for the semantics of type (2) and type (3) modifiers as well. This enables us to stick to the fundamental insights concerning modification proposed above. In particular, we may adhere to the assumption that, first, modification concerns the designated argument of the modifier and the referential argument of the modificandum and, secondly, that the proper semantic operation for modelling intersective modification is conjunction of Semantic Forms.

What should be clear by now is that a reformulation of the combinatorial schema for modification should also take into account syntactic structure, which does not play a significant role in the above definition. In fact, two further measures are required to cope with the data: We must consider an additional ramification within the combinatorial schema and an additional referential argument that comes into play within the functional shell of VP.

Let us turn to the semantics of type (2) modifiers first. The problem of the existing combinatorial schema w.r.t. type (2) modifiers is that it links the situational referent of the verb tightly to the entity that is located in space. But, as we have seen in Section 1, this assumption leads to undesired results for type (2) modifiers. So, 
let us try to figure out whether we can make out on strictly semantic grounds an alternative candidate for being located.

(23) a. Die Bankräuber sind auf Fahrrädern geflüchtet.

'The bank-robbers have on bicycles fled.'

b. Der Koch hat die Hähnchen in einer Marihuana-Tunke zubereitet. 'The cook has the chickens in a Marihuana sauce prepared.'

c. Maria zog Paul am Kragen in den Flur. 'Mary dragged Paul at.the collar into the corridor.'

d. Paul hat Maria auf dem Rücken getragen.

'Paul has Mary on the back carried.'

(23) comprises a representative collection of type (2) modifiers: (23.a) suggests that it is the entity being referred to by the designated argument of the verb, viz. the bank-robbers, that is being located at the region referred to by the modifier. In (23.b) the corresponding entity LE is provided by the internal argument of the verb, that is, the chickens. So, a possible conclusion to be drawn from this could be that the relevant entity being located in space is always provided by some explicit argument of the verb. However, this fails to be the correct generalization, as can be seen when taking into account e.g. (23.c) or (23.d). In the case of (23.c) neither Mary nor Paul are located at the collar. Mary's hand would be a plausible LE candidate, according to our world knowledge. But the actual context might equally well provide evidence for some other kind of instrument that is brought into contact with the collar (e.g. a pair of nippers). Thus, at the level of SF there are no reliable conclusions to be drawn about the identification of LE. (23.d) is an even more intricate case. Here, we are faced with several options of how to link up the property of being located on the back within this situation. First, it might be the case that Mary is located on top of Paul's back. Secondly, the locative modifier might characterize the position of Mary while Paul is carrying her. And third, it might also characterize Paul's position, while he is carrying Mary. Again, LE cannot be determined with any degree of certainty at the level of SF.

So, what do all these expressions involving type (2) modifiers have in common? Actually, they share the information that the entity being located by the prepositional phrase takes part in the situation denoted by the verb, but is semantically underspecified otherwise. Thus, in order to characterize the abstract, context-independent common meaning of all cases at hand, LE should be replaced by a free variable at SF that is subject to a conceptual condition on instantiation. Roughly, the condition says that the variable must be instantiated with respect to the internal structure of the situational referent at CS. ${ }^{10}$ Thus, the Semantic Form of all type (2) modifications follows the general schema given in (25). This schema differs from the type (1) schema (repeated in (24)) only with respect to the free variable $x$ that is introduced instead of the situational argument.

(24) Type (1) modifiers: ... $\lambda s$ [ s INST [ ... ] \& LOC (s, SPACE-FUNC (RO))]

(25) Type (2) modifiers: ... $\lambda s$ [ s INST [ ... ] \& LOC (x, SPACE-FUNC (RO))]

The proposal made here amounts to the claim that besides establishing a direct link between the designated argument of the modifier and the referential argument of the modificandum by means of semantic identification, the combinatorial schema for modification must license additionally an indirect linking of the designated and the referential argument. That is, a linking mediated by a free variable. Of course, this option is limited strictly to the specific syntactic adjunction 
site in immediate proximity to the verb. A precise definition of the combinatorial schema will be given below.

When turning now to the type (3) modifiers, we have to bear in mind that they take a syntactic base position that is configurationally above the functional category Infl; cf. Section 3. In order to determine the semantics for type (3) modifiers, we have to check therefore whether the combination of Infl and VP causes some change in argument structure that is relevant for composition. It is commonly assumed that Infl specifies the referential properties of VP. Usually, existential quantification of the referential argument accounts for the job; cf. e.g. Bierwisch (1988), Zimmermann (1992). ${ }^{11}$ But there is ample evidence that things are slightly more complex. Taking up a proposal made by Löbner (1990), I have argued in Maienborn (1993) that the denotation of a VP is referentially specified with respect to a so-called "reference situation" $\left(s_{R}\right)$. $s_{R}$ provides a referential frame for the propositional content of the sentence. It therefore delimits the range in which the proposition is claimed to hold. Actually, some device in the spirit of $s_{R}$ can be found in several recent investigations, especially in work on tense and aspect. 12 The peculiarity of the present proposal is that, first, it assumes a whole reference situation, instead of splitting it up into several isolated parameters (e.g. time index, space index, world index, etc.) and, secondly, it provides a compositional account for $s_{R}$. That is, $s_{R}$ is introduced into $S F$ by Infl in the course of semantic composition.

Without a doubt, the semantics of Infl and its impact on the referential specification of VP deserves much more clarification. For the time being, I will assume a Semantic Form for Infl that introduces $s_{R}$ as its referential argument and anchors the SF of the verbal phrase (given by the complex predicate $Q(x)$ ) w.r.t. $\mathrm{S}_{\mathrm{R}}$, as is shown in (26). ${ }^{13}$ For the sake of simplicity, a semantically underspecified relation REL holds between $S_{R}$ and the VP-denotation in (26). REL has to be spelled out properly (e.g. as a temporal or conditional relation) at the conceptual level; cf. Maienborn (1993) for illustrations.

\section{(26) $I^{0}: \lambda \mathrm{Q} \lambda \mathrm{x} \lambda \mathrm{s}_{\mathrm{R}}\left[\mathrm{REL}\left(\mathrm{s}_{\mathrm{R}},[\mathrm{Q}(\mathrm{x})]\right)\right]$}

The present proposal of the Semantic Form of Infl should be understood as a first attempt to single out what is really going on semantically within the functional shell of VP - a matter that extends far beyond the issue being discussed here. The main point for our current topic is that at a certain stage of semantic composition within the functional shell of VP, the situational referent of the verb is not available anymore as referential argument for modification and this place is taken by $s_{R}$. Under this assumption, the semantics of type (3) modifiers can be accounted for straightforwardly by the original modification schema. The job of type (3) modifiers simply consists in locating the reference situation. Since $s_{R}$ figures as referential frame for the proposition, the localization of $s_{R}$ in space gives us the spatial frame alluded to in the discussion of the sentences under (3). In this view, the specific semantics of type (3) modifiers turns out to be rather a side-effect of semantic composition. Their peculiarities can be traced back to the change in argument structure that has taken place before the type (3) modifier shows up. The general schema of type (3) modifiers is given in (27):

\section{Type (3) modifiers: ... $\lambda s_{R}[$ REL (sR, [... ]) \& LOC (sR, SPACE-FUNC (RO))]}

Having spelled out the semantics of locative VP-modifiers so far, I would like to add a short remark on some interconnections with the so-called "individual level predicate/stage level predicate distinction" (ILP/SLP); cf. e.g. Kratzer (1989), Diesing (1992). ${ }^{14}$ If we assume, following Kratzer (1989), that lexical entries of 
ILP lack a situational referent, then the theory of modification presented here predicts that verbs qualified as ILP can not be combined with locative modifiers of type (1) and (2), since the combinatorial schema for modification requires that the modificandum provides a referential argument to be linked with the designated argument of the modifier. Thus, the application of the schema fails in case we want to combine an ILP with a locative modifier. This rules out such ungrammatical sentences as (28) with typical ILP verbs like heißen: (to be called) or ähneln (to resemble).
a. *Der Junge heißt
vor dem Haus Paul.
'The boy has-the-name in-front-of the house Paul.'
(The boy is called Paul in front of the house.)

b. *Paul ähnelt an der nächsten Ecke seinem Bruder.

'Paul resembles at the next corner his brother.'

On the other hand, the theory predicts that ILP expressions can be combined with type (3) modifiers because these do not link up to the verb's referential argument but to the referential argument of Infl, $\mathrm{s}_{\mathrm{R}}$. And this is actually the case, as demonstrated e.g. by the well-formed sentences in (29). 15

(29) a. Zuhause heißt Paul "Zuckerpuppe".

'At-home has-the-name Paul "sugar doll".'

b. Auf diesem Bild ähnelt Paul seinem Bruder.

'On this picture resembles Paul his brother'

The diagram given below summarizes this approach to the compositional semantics of locative VP modifiers and gives a formal definition of the modification schema advocated throughout the paper. This schema is part of a small set of combinatorial schemata that determine the mapping between syntactic and semantic structure. ${ }^{16}$ A combinatorial schema specifies the syntactic configuration it applies to, as well as certain conditions on the argument structure of the expressions that are to be combined. On this basis, it determines the shape of the argument structure of the resulting complex expression and its Semantic Form. Within such a schema, the argument structure (or: $\theta$-grid) of a linguistic expression can be represented as a list of $\theta$-roles; cf. the $\theta$-grid $X$ for the category $X$ in (30.a). A $\theta$-role, in turn, is a quadruple that consists of a variable binding operator, a feature set $\theta \mathrm{F}$, a domain $\mathrm{D}$, and a variable $\mathrm{v}$; cf. the representation of the $\theta$-role $\theta_{\mathrm{a}}$ in (30.b): 17
a. $\theta$-gridx $=\left[\begin{array}{lll}\theta_{1} & \ldots & \theta_{n}\end{array}\right]$
b. $\theta_{\mathrm{a}}=\left(\lambda \theta \mathrm{F}_{\mathrm{a}} \mathrm{D}_{\mathrm{a}} \mathrm{v}_{\mathrm{a}}\right)$

The modification schema following below, identifies $v_{n}$ as referential argument of the head constituent $X$ and $v_{a}$ as designated argument of the adjunct YP. While X may still have further unsaturated arguments, YP must have saturated all its arguments except $\mathrm{v}_{\mathrm{a}} \cdot{ }^{18}$ Given this structural configuration, the modification schema determines that the $\theta$-grid of the complex expression is inherited from the syntactic head $X$ and the resulting $S F$ is based on conjunction. In the course of building up the complex $S F, v_{n}$ and $v_{a}$ are either directly linked by identification (case a) or indirectly linked by a free variable $\mathrm{v}$ (case $\mathrm{b}$ ), depending on the level of adjunction. In our case, the first condition accounts for type (1) and type (3) modifiers whereas the second condition accounts for type (2) modifiers. 


\begin{tabular}{|lll|}
\hline Lexicon: & - PP $_{\mathrm{LOK}}:$ & $\lambda \underline{x}[\operatorname{LOC}(\mathrm{x}, \operatorname{SPACE}-\mathrm{FUNC}(\mathrm{RO}))]$ \\
& $\bullet$ Verb: & $\ldots \lambda s[\mathrm{~s}$ INST $[\ldots]]$ \\
& $\bullet \mathbf{I}^{\mathbf{0}}:$ & $\lambda \mathrm{Q} \lambda \mathrm{x} \lambda \mathrm{s}_{\mathrm{R}}\left[\operatorname{REL}\left(\mathrm{s}_{\mathrm{R}},[\mathrm{Q}(\mathrm{x})]\right)\right]$ \\
\hline
\end{tabular}

Grammar:
Given a syntactic structure: $\mathrm{X}^{\mathrm{i}} \rightarrow \ldots$ YP $\ldots \mathrm{X}^{\mathrm{i}} \ldots \mathrm{YP} \ldots$
and the $\theta$-grids: $\theta$-grid $\mathrm{X}=\left[\ldots \theta_{\mathrm{n}-1}\left(\lambda \theta \mathrm{F}_{\mathrm{n}} \mathrm{D}_{\mathrm{n}} \mathrm{v}_{\mathrm{n}}\right)\right]+\mathrm{ref} \in \theta \mathrm{F}_{\mathrm{n}}$,
$\quad \theta$-grid $\mathrm{Y}=\left[\left(\lambda \theta \mathrm{F}_{\mathrm{a}} \mathrm{D}_{\mathrm{a}} \mathrm{v}_{\mathrm{a}}\right)\right]+$ desig $\in \theta \mathrm{F}_{\mathrm{a}}$ and $\mathrm{v}_{\mathrm{n}} \in \mathrm{D}_{\mathrm{a}}$
$\theta$-gridX is the $\theta$-grid of the complex expression and
a) for $\mathrm{i} \geq 1:\left[\mathrm{SF}_{\mathrm{X}} \&\left(\lambda \mathrm{v}_{\mathrm{a}}\left[\mathrm{SF}_{\mathrm{Y}}\right]\right)\left(\mathrm{v}_{\mathrm{n}}\right)\right]$ or
b) for $\mathrm{i}<1:\left[\mathrm{SF}_{\mathrm{X}} \&\left(\lambda \mathrm{v}_{\mathrm{a}}\left[\mathrm{SF}_{\mathrm{Y}}\right]\right)(\mathrm{v})\right]$ with $\mathrm{v} \in \mathrm{D}_{\mathrm{a}}$
its Semantic Form.

- Type (1) modifiers:

$\left[\mathrm{V}_{\mathrm{V}}, \mathrm{PP}\left[\mathrm{V}_{\mathrm{V}} \ldots\right]\right]: \ldots \lambda \mathrm{s}[\mathrm{s}$ INST $[\ldots] \&$ LOC $(\mathrm{s}, \mathrm{SPACE}-\mathrm{FUNC}(\mathrm{RO}))]$

Type(2) modifiers:

$[\mathrm{v} P P[\mathrm{v} \ldots]]: \ldots \lambda s[\mathrm{~s}$ INST $[\ldots] \&$ LOC $(\mathrm{x}, \operatorname{SPACE}-\mathrm{FUNC}(\mathrm{RO}))]$

Type (3) modifiers:

$\left[{ }_{\text {IP }}\right.$ PP $\left.\left[{ }_{\text {IP }} \ldots\right]\right]: \ldots \lambda s_{R}\left[\operatorname{REL}\left(s_{R},[\ldots]\right) \& \operatorname{LOC}\left(s_{R}, \operatorname{SPACE}-F U N C(R O)\right)\right]$

It should be emphasized that the model developed here suffices to account for the requirements concerning lexicon and grammar raised in Section 2 . That is, we can do without multiple lexical entries for verbs or prepositions, and instead retain rather uncontroversial standard representations (with a big caveat w.r.t. the SF of Infl). In particular, locative PPs are analyzed rigorously as (complex) oneplace predicates over objects or situations that establish a particular spatial relationship. As concerns the grammar, compositionality is upheld by the assumption of a single, syntactically tuned combinatorial schema that licenses modification.

With these rather parsimonious assumptions concerning lexicon and grammar we can derive semantic structures for the three types of locative VP-modifiers that differ with respect to the entity that is located in space: the situational referent of the verb in the case of type (1) modifiers, a semantically underspecified entity that is to be identified within the conceptual structure of the situational referent in the case of type (2) modifiers, or a reference situation, which restricts the range of a proposition in the case of type (3) modifiers.

These Semantic Forms provide the structural sources of the ambiguities shown in Section 1 and they reflect the genuinely linguistic portion underlying the meaning variances observed with locative VP-modifiers. Finer grained meaning distinctions below this level of semantic differentiation are not reflected syntactically or prosodically. Thus, they are not transparent within grammar and should therefore be accounted for by the conceptual system. 
In particular, the conceptual system has to motivate the additional nonspatial meaning relations that are superimposed on the regular spatial relation. However, the Semantic Forms of the locative modifiers already provide the reason why these meaning variances show up typically with type (2) and type (3) modifiers but not with type (1) modifiers: Notice that within the SF of both, type (2) as well as type (3) modifiers, there is a component that is semantically underspecified, namely a free variable in the case of type (2) modifiers and a underdetermined relation REL in the case of type (3) modifiers. That is, the Semantic Form restricts only minimally the range of possible conceptual specifications at this point. Hence, contextual conditions and genuinely conceptual knowledge about the world obtain increasing influence on the interpretation of these meaning components. On the other hand, there is no comparable semantic underspecification in the SF of type (1) modifiers. Therefore, they are not subject to such an interpretative variation when conceptually specified.

\section{Conceptual Structure}

Although the primary focus of the present paper lies on the grammatically transparent meaning skeleton, a few remarks about the corresponding conceptual structure shall be added in order to complete the general picture of the semantics of locative VP-modifiers. In particular, the emergence of instrumental, modal, temporal or conditional interpretations observed with type (2) and type (3) modifiers are of interest here. 19

I have argued in Maienborn (1993) that these non-spatial meaning relations that are superimposed on the semantically established spatial relations fall out naturally from principles governing conceptual knowledge. The interpretation of sentences with locative modifiers makes use of independently established conceptual knowledge sources. In the case of type (2) modifiers, for instance, knowledge about functional relationships as well as domain specific part-whole-relations is accessed frequently. Furthermore, conceptual knowledge about spatial properties of objects in terms of axis, sides, surfaces, etc. is exploited extensively. ${ }^{20}$ The crucial point here is that these conceptual notions are systematically interlinked with basic spatial relations. If we look e.g. at functional relationships, it can be observed that a certain spatial configuration is required generally in order to establish a functional connection. Take for instance extrinsic movement, i.e. movement where an extrinsic means of locomotion is employed: This kind of movement presupposes the existence of some relation of spatial support holding between a vehicle and the moved entity, otherwise the latter could not benefit from the motion of the vehicle in the intended sense. More generally speaking, spatial relations provide basic ingredients for building up all kinds of complex conceptual structures. In particular, the spatial relations of inclusion, contact, and support figure among the basic building elements of the conceptual system.

This kind of knowledge has to be accounted for, irrespective of whether we are interested in the semantics of locative modifiers or not. But, once established, its significance for the interpretation of e.g. type (2) modifiers becomes obvious, because it provides the "slots" to which the information of the modifier can be linked. That is, the specific contribution of type (2) modifiers consists of supplying further information about a spatial configuration pre-established within the internal conceptual structure of a situational referent.

The sentences in (31) illustrate this point. Each of them refers to a situation of extrinsic movement. Thus, they all presuppose the existence of a vehicle that stands in a relation of spatial support to the moved entity. Given this configuration, 
the spatial relation expressed by the type (2) modifier can be integrated into the internal conceptual structure of the situational referent thereby providing a conceptual instantiation of the free variable for LE that was left unspecified at the level of SF. In the cases at hand, the integration succeeds because the internal argument of the modifier (RO) qualifies as a suitable means of locomotion and the spatial relation provided by the locative preposition ((31.a): support, (31.b): inclusion, (31.c): contact) turns out to be compatible with the spatial configuration preestablished by the situational referent. ${ }^{21}$ Thus, RO can be identified with the presupposed vehicle. This identification in turn yields a conceptual instantiation of the modifier's free variable for LE, viz. the moved entity.

(31) a. Die Bankräuber ritten auf Eseln davon.

'The bank-robbers rode on donkeys away.'

b. Die Bankräuber flohen im Taxi.

'The bank-robbers fled in.the cab.'

c. Tarzan schwingt sich an einer Liane von Baum zu Baum.

'Tarzan is swinging himself on a liana from tree to tree.'

This analysis carries over to the conceptual interpretation of (32.a). In (32.b), the integration of the modifier fails however, because the internal structure of the situational referent does not provide an extrinsic means of locomotion. Therefore, the modifier does not find a suitable slot to which it can link its RO. Consequently, no instantiation of the free variable for LE is obtained. ${ }^{22}$ Finally, in (32.c), a type (2) modifier fails to be integrated due to the type of spatial relation supplied by the preposition which is not compatible with the spatial configuration of support demanded by the situational referent. Thus, the bicycle cannot be identified as the means of locomotion in (32.c).

(32) a. Paul fährt auf seinem Fahrrad durch den Park.

'Paul rides on his bike through the park.'

b. \$Paul rennt auf seinem Fahrrad durch den Park.

'Paul runs on his bike through the park.'

c. \$Paul fährt bei seinem Fahrrad durch den Park.

'Paul drives near his bike through the park.'

From this brief sketch we might conclude that the reason why type (2) modifiers can take on an instrumental reading is simply that in the course of integrating the information contained in the modifier into the internal structure of the situation, the referent of the internal argument is identified with an entity which already figures as an instrument within the internal structure of the situation. This analysis carries over to the modal readings of type (2) modifiers, as well. Under this view, the non-spatial meaning contributions turn out to be simply an effect of applying the conceptual machinery to linguistically filtered structures. Thus, the approach developed here must not assume that locative prepositions may occasionally have a defective or in some sense mutated semantic structure, but accounts for the peculiar interpretation of locative modifiers by emphasizing exactly their genuinely spatial meaning.

To conclude, the present paper has outlined a model of semantic composition which derives adequate semantic structures for each of the three potential adjunction sites of locative VP-modifiers. Within this model, observable distinct readings of locative modifiers are traced back to elementary combinatorial mechanisms of the grammatical and the conceptual system, both operating on independently motivated lexical structures. 


\section{Endnotes}

* The work reported on here is based on my doctoral dissertation that was presented to the faculty of language and literature of the University of Hamburg in June 1994. I am indebted to my advisor, Christopher Habel, and to Carsten Günther and Andrea Schopp for their valuable support. The present version has benefited substantially from discussions with Ewald Lang, Sue Olsen, Renate Steinitz, and Ilse Zimmermann as well as from many helpful suggestions and comments of the SALT V conference audience. Special thanks go to Sue for checking my English.

1 The present paper deals exclusively with locative modifiers of verb phrases. In some cases, the data referred to might allow for an NP-reading, as well, but this is of no interest for the current issue.

2 For a discussion of the conditions on the placement of neutral stress in German cf. e.g. von Stechow \& Uhmann (1986), Jacobs (1991).

3 In the following, primary sentence accent is marked by capital letters. For the present purposes, word internal accent realization can be neglected.

4 For a discussion of VP-topicalization in German cf. e.g. Haider (1993).

5 The present analysis indicates, furthermore, that arguments and adjuncts alternate within the verbal projection, in German. Therefore, it supports neither the classical view that verbs first combine with their arguments before being combined with adjuncts nor the assumption that all VP-adjuncts are base-generated below the arguments of the verb, which has become popular since Larson $(1988,1990)$.

6 Actually, this is a slight simplification. Type (2) modifiers may be separated from the verb by a predicative phrase (e.g. resultatives, directional phrases). The exact nature of the verb's immediate projection in German is currently the subject of intensive debate; cf. Steinitz (1989), Frey (1993), Maienborn (1993).

7 For the sake of simplicity, I have neglected possible splittings of the functional VP-shell into e.g. AGR-, Tense-, or Neg-phrases. The analysis does not depend crucially on this assumption, however.

8 The designated argument of a lexical category corresponds to its syntactically and semantically most prominent argument; cf. the notion of "external argument" in Williams (1981). Adopting the notational convention from Williams (1981), the designated argument is marked by underlining.

9 The semantic type of $\mathrm{x}$ is restricted to entities belonging either to the domain of objects or to the domain of situations (events or states).

10 This analysis of type (2) modifiers shows some striking similarities to the analysis of German mit-PPs (Engl.: with) proposed by Strigin (1995). Using a somewhat different framework, Strigin assumes that the semantics of mit establishes an unspecified relation between the referent of the internal argument and an arbitrary entity that takes part in the situation referred to by the verb. The actual entity as well as the specific relation holding is determined w.r.t. world knowledge and contextual information. From this point of view, the only difference between verbal mit-modifiers and locative type (2) modifiers is that the former leave the corresponding relation semantically unspecified whereas the latter establish a specific spatial relationship. Interestingly, the tests that I have used to determine the syntactic base structure position of locative modifiers in Section 3 yield the same results for mit-PPs as for type (2) modifiers: Like locative type (2) modifiers, mit-modifiers have a base position in close proximity to the verb. Given the syntactic parallels, the semantic commonalties are not surprising anymore. The present strictly compositional framework ensures that locative type (2) modifiers and mitmodifiers share also the mode of semantic combination.

11 Cf. also the notion of "existential closure of the VP" in the Kamp (1981)/Heim (1982) framework and subsequent work like Kratzer (1989) and Diesing (1992).

12 Cf. e.g. the notion of "topic time" in Klein (1992).

13 The semantic operation that handles the combination of a functional head and its complement is functional composition; cf. Maienborn (1993) for details. 
14 This distinction goes back to Carlson (1978) and says roughly that ILP refer to permanent properties of individuals whereas SLP refer to temporary properties (so-called "stages").

15 Due to lack of space, I cannot go into more detail here, although the analysis of locative modifiers sheds also some light on some quite problematic semantic aspects of the ILP/SLP distinction that are neglected in the current syntactically oriented discussion. These concern the content of the ILP/SLP distinction (e.g. its notorious context dependency) as well as its formal representation in LF; cf. Maienborn (1993) for a detailed discussion.

16 Combinatorial schemata therefore correspond to operations on argument structure in the framework of Higginbotham (1985) (viz. $\theta$-marking, $\theta$-identification, $\theta$-binding). In Abb \& Maienborn (1994), a model of the syntax-semantics mapping for (locative) PPs that, besides modification, includes also PPs in argument position and in predicative constructions is worked out in detail within the framework of HPSG.

17 The feature set $\theta \mathrm{F}$ determines whether a given $\theta$-role figures as referential $([+\mathrm{ref}])$, designated ([+desig]) or internal ([-ref, -desig]) argument. The domain D restricts the semantic type of an argument by specifying the admissible domain of its referent. ( $D_{0}$ : domain of objects, $D_{S}$ : domain of situations, etc.). Thus, the designated argument of a locative preposition $(\lambda \underline{\mathbf{x}})$ has the formal representation (i); and the referential argument of a situative verb ( $\lambda s)$ has the representation given in (ii):

(i) $\left(\lambda\{+\right.$ desig $\left.\} D_{S} \cup D_{O} v_{a}\right)$

(ii) $\left(\lambda\{+\right.$ ref $\left.\} D_{S} v_{n}\right)$

18 The condition $v_{n} \in D_{a}$ ensures compatibility of semantic types.

19 For the sake of illustration, I will concentrate on the instrumental reading of locative type (2) modifiers in the following; but cf. Maienborn (1993) for a more comprehensive account.

$20 \mathrm{Cf}$. the theory of positional and dimensional properties of spatial objects developed in Lang $(1989,1995)$, Lang \& Carstensen \& Simmons (1991). This theory was originally developed in order to account for the conceptual interpretation of dimensional adjectives. In the meantime, it has proven to provide an adequate conceptual basis for an increasing number of further crosslinguistic phenomena, with locative VP-modification figuring among them. In my view, this strongly supports the need (and benefit) of a strict distinction between a language-specific and a language-independent part of meaning representation.

21 Strigin (1995) proposes abduction as a suitable inference device for this kind of conceptual reasoning.

22 The symbol "§" is used to mark conceptual ill-formedness.

\section{References}

Abb, Bernd \& Claudia Maienborn (1994): Adjuncts in HPSG. In: H. Trost (ed.), Conference Proceedings of KONVENS 94: Verarbeitung natürlicher Sprache. Wien, 28. - 30. September 1994, Berlin: Springer, $13-22$.

Bierwisch, Manfred (1982): Formal and Lexical Semantics. Linguistische Berichte, 80/82, 3 - 17.

Bierwisch, Manfred (1988): On the Grammar of Local Prepositions. In: M. Bierwisch \& W. Motsch \& I. Zimmermann (eds.), Syntax, Semantik und Lexikon. (= studia grammatica IXXX), Berlin: Akademie-Verlag, 1 - 65.

Bierwisch, Manfred \& Ewald Lang (1989): Somewhat Longer - Much Deeper - Further and Further. Epilogue to the Dimension Adjective Project. In: M. Bierwisch \& E. Lang (eds.), Dimensional Adjectives: Grammatical Structure and Conceptual Interpretation. Berlin et al.: Springer, $471-514$.

Carlson, Greg (1978): Reference to Kinds in English. Dissertation, University of Massachusetts, Amherst.

Dowty, David R. (1979): Word Meaning and Montague Grammar. Dordrecht: Reidel.

Diesing, Molly (1992): Indefinites. Cambridge/Mass.: MIT Press.

Frey, Werner (1993): Syntaktische Bedingungen für die semantische Interpretation. Über Bindung, implizite Argumente und Skopus (= studia grammatica XXXV), Berlin: Akademie-Verlag. 
Haider, Hubert (1993): Deutsche Syntax-generativ. Tübingen: Narr.

Heim, Irene (1982): The Semantics of Definite and Indefinite Noun Phrases. Dissertation, University of Massachusetts, Amherst.

Higginbotham, James (1985): On Semantics. Linguistic Inquiry, 16: 547 - 593.

Höhle, Tilman (1982): Explikation für "normale Betonung" und "normale Wortstellung". In W. Abraham (ed.): Satzglieder im Deutschen. Tübingen: Nar, 75 - 154.

Jacobs, Joachim (1991): Focus Ambiguities. Journal of Semantics8, 1 - 36.

Kamp, Hans (1981): A Theory of Truth and Semantic Representation. In: J. Groenendijk \& T. Janssen \& M. Stokhof (eds.): Formal Methods in the Study of Language. Mathematisch Centrum: Amsterdam, 277 - 322.

Klein, Wolfgang (1992): The present perfect puzzle. Language 68/3, 525 - 552.

Kratzer, Angelika (1989): Stage and Individual Level Predicates. In: Papers on Quantification, NSF Grant Report, Department of Linguistics, University of Massachusetts, Amherst.

Lang, Ewald (1989): The Semantics of Dimensional Designation of Spatial Objects. In M. Bierwisch \& E. Lang (eds.), Dimensional Adjectives: Grammatical Structure and Conceptual Interpretation. Berlin et al.: Springer, $263-417$.

Lang, Ewald (1995): Basic Dimension Terms: A first look at universal features and typological variation. In: A. Alexiadu et. al. (eds.), FAS Papers in Linguistics, 1, FAS (Research Center for General Linguistics, Typology and Universals), Berlin.

Lang, Ewald \& Kai-Uwe Carstensen \& Geoffrey Simmons (1991): Modelling Spatial Knowledge on a Linguistic Basis. Theory - Prototype - Integration. Lecture Notes in Artificial Intelligence, Vol. 481, Berlin et al.: Springer.

Larson, Richard K. (1988): On the Double Object Construction. Linguistic Inquiry 19/3: 335 391.

Larson, Richard K. (1990): Double Objects Revisited: Reply to Jackendoff. Linguistic Inquiry 21/4: $589-632$.

Löbner, Sebastian (1990): Wahr neben Falsch. Duale Operatoren als die Quantoren natürlicher Sprache. Tübingen: Niemeyer.

Maienborn, Claudia (1993): Situation und Lokation: Die Bedeutung lokaler Adjunkte von Verbalprojektionen. Dissertation, University of Hamburg.

von Stechow, A. \& S. Uhmann (1986): Some Remarks on Focus Projection. In: W. Abraham \& S. de Meij (eds.), Topic, Focus and Configurationality. Papers from the $6^{\text {th }}$ Groningen Grammar Talks 1984. Amsterdam/Philadelphia: Benjamins, 295 - 320.

Steinitz, Renate (1989): V ${ }^{\mathrm{u}}, \mathrm{I}^{\mathrm{y}}$ und $\mathrm{I}^{\mathrm{z}}$ : Überlegungen zum Prädikativ. Linguistische Studien A, Arbeitsberichte, 194, Berlin: Akademie der Wissenschaften der DDR, 210 - 234.

Strigin, Anatoli (1995): Abductive inference during update: the German preposition mit (with). In this volume.

Williams, Edwin (1981): Argument Structure and Morphology. The Linguistic Review, 1, 81 144.

Wunderlich, Dieter (1991): How do prepositional phrases fit into compositional syntax and semantics? Linguistics 29: $591-621$.

Wunderlich, Dieter \& Michael Herweg (1991): Lokale und Direktionale. In: A. von Stechow \& D. Wunderlich (eds.), Semantik - Semantics. Ein internationales Handbuch der zeitgenössischen Forschung - An International Handbook of Contemporary Research. Berlin, New York: de Gruyter, $758-785$.

Zimmermann, Ilse (1992): Der Skopus von Modifikatoren. In: I. Zimmermann \& A. Strigin (eds.), Fügungspotenzen (= studia grammatica XXXIII). Berlin: Akademie-Verlag, 251 279.

\section{Claudia Maienborn}

Humboldt-Universität zu Berlin

Philosophische Fakultät II

Institut für deutsche Sprache und Linguistik

Unter den Linden 6, D-10099 Berlin, Germany

e-mail: Claudia=Maienborn@rz.hu-berlin.de 